\title{
Os sentidos dos objetos mortos: medições na comunicação urbana
}

\author{
Denise P. C. Tangerino \& Diogo Andrade Bornhausen
}

\section{Resumo:}

Resenha do livro O parque dos objetos mortos: e outros ensaios de comunicação urbana.

\section{Palavras Chave:}

Comunicação, mídia, cidade, Fabrício Silveira

\begin{abstract}
:
Book review O parque dos objetos mortos: e outros ensaios de comunicação urbana.
\end{abstract}

Keywords:

Communication, media, city, Fabrício Silveira.

SILVEIRA, Fabrício. O parque dos objetos mortos: e outros ensaios de comunicação urbana. Porto Alegre: Armazém Digital, 2010. 126 pp.

Resultante de distintos projetos de investigação acadêmica realizados entre 2000 e 2006 na cidade de Porto Alegre, O parque dos objetos mortos: e outros ensaios de comunicação urbana reúne uma série de ensaios realizados por Fabrício Silveira. Com o enfoque de pesquisa nas interfaces dos temas cidade e comunicação, o texto está estruturado em cinco capítulos, sendo que cada parte mantém suas marcas históricas e linhas gerais das publicações originais, porém atribuindo nova vitalidade e trânsito às discussões.

A composição da capa, com elementos tipográficos e ilustrações manuais do ambiente urbano dispostas em fundo cinza, revela a primeira pista das temáticas e abordagens da representação da cidade que o leitor encontrará ao longo do livro. Justapostas, decalcadas e fragmentadas, as imagens da capa táxi, televisão, lixos, descartes, prédios, grades - remetem aos objetos analisados ao longo dos artigos, destacando a urbes como espaço de fluxos, entrecruzamentos e disputas simbólicas que formam o ambiente comunicativo.

Interessado no debate teórico sobre os temas de comunicação e cidade, Silveira procura analisar a urbes como palco de experimentação de sociabilidades e sensisibilidades tecno-comunicacionais, especialmente engendradas pela proliferação de novas mídias e pelo surgimento de novos aparatos tecnológicos, e como cenário fundamental para compreender as formas de apropriação e ressignificação do espaço público pelos sujeitos sociais. Ao ver a cidade como ambiente em que se geram constantes trocas simbólicas, abastecidas pela reconfiguração da mídia, os textos percorrem específicas abordagens metodológicas e justificadas experiências de pesquisa que se adequam às diversas situações analisadas.

Em seu primeiro ensaio, que também dá título ao livro, o autor se vale de um amplo respaldo 
teórico que "vai de Lévi-Strauss a Bourdieu, passando por Bauman e Certeau, para culminar em Benjamin" (SILVEIRA, 2010: 17) para formar um caminho metodológico capaz de interpretar o universo de produção, circulação, consumo e significação dos bens materiais midiáticos da atualidade. Em sua pesquisa inicial está a descoberta dos efeitos da mídia de massa em uma população de baixa renda na periferia de Porto Alegre e, especificamente, como respondem à cobertura televisiva sobre a celebração dos 500 anos do Brasil. Em um segundo momento, a partir da indústria de reciclagem que se estabeleceu nesta mesma comunidade, o autor analisa através dos registros fotográficos e entrevistas a forma como os objetos percorrem um ciclo de consumo - cultural e de materialidades - na nossa sociedade até o momento em que são descartados e reutilizados pelos trabalhadores.

Com a ampla quantidade de imagens feitas sobre estas condições, Silveira questiona a forma como os objetos da cultura são assimilados atualmente e sobre a maneira como esta dinâmica é capaz de revelar uma significativa leitura social e comunicativa dos hábitos atuais. Através do que é identificado como lixo, do que não mais interessa, manifesta-se a compulsão pelo descarte e pela efemeridade com que a sociedade lida com os próprios valores. Valores que só ali, como dejetos, tornam-se plenamente materializáveis, como é o caso da televisão encontrada pelo autor.

Em uma retrocessão do fim último do aparelho, o segundo ensaio, "Mediações e cia.", busca analisar os processos de recepção, ainda pouco estudados, gerados na relação entre televisão, espaço urbano e interações coletivas. Tendo como locus de observação dois bares da capital gaúcha, onde tal mídia ocupa locais de destaque, tanto pra quem ali está como para os transeuntes que veem suas imagens à distância. Compreender, em uma abordagem etnográfica, as relações que se estabelecem a partir do uso do aparelho em ambientes coletivos é o principal objetivo do autor.

Recorrendo ao conceito de medialidade, elaborado por Hans Ulrich Gumbrecht, o autor confere uma sutil análise ao "espantoso leque de usos e funcionalidades" que o aparelho tem em tais espaços e sobre as pessoas que ali estão, como, por exemplo, relações hierárquicas, mudanças de hábitos alimentares e a formação de novas visualidades. Remete à necessidade de construir um conjunto teórico capaz de lidar com estas situações "fluidas e flexíveis", "e à processualidade um tanto insondável destes usos/consumos midiáticos" (SILVEIRA, 2010: 56).

Em seu terceiro ensaio, "Televisores e corpos móveis na metrópole", o autor elabora uma particular análise de um elemento bastante presente nas cidades e que foi alvo de poucas pesquisas até então, os taxistas, ou melhor, a relação dos taxistas com o ambiente urbano, suas observações, seus pontos de vista e a forma como interagem com todos os elementos da metrópole. Partindo em exercício caracteristicamente benjaminiano, como é sua proposta, Silveira vai em busca das sensibilidades expostas na urbes, seus detalhes, suas belezas e suas imagens que só poderiam ser auxiliadas por este personagem.

Em um segundo momento, continuando com as entrevistas e sua própria observação, o autor revela, novamente, a presença da televisão, só que desta vez dentro dos táxis. As razões, as funcionalidades e as histórias são apresentadas como um jogo entre dois mundos, de um lado o mundo vivido e do outro a mediação do televisor que, embora os taxistas neguem, claramente se mescla às relações deles com a metrópole, com seus passageiros e na forma como observam a realidade. O taxista torna-se o flâneur contemporâneo, vive a realidade através de sua observação ao mesmo tempo em que também é mediado pela programação constante.

Já o penúltimo capítulo, “Assinaturas urbanas", faz uma breve contextualização das transformações dos usos, das apropriações do urbano e da aceleração da vida desde o século XIX. Recorrendo inicialmente às impressões de Nicolau Sevcenko sobre a revitalização do espaço público, Silveira demonstra a centralidade da cidade como suporte de diversas intervenções que poderiam ser classificadas como disputas políticas. Nesse contexto, os sujeitos sociais se apropriariam semioticamente do cenário urbano projetando e materializando diversas assinaturas - grafites e pichações -, ações que Michel de Certeau classificou como "textos de resistência" (apud SILVEIRA, 2010: 79).

Com este enfoque o autor procura fazer uma leitura abrangente destes e de suas comunicabilidades quando ocupam a arena pública. Faz, com isso, três distinções que configuram a forma como as imagens e textos se mesclam aos diversos cenários: aos que possuem a lógica do mercado, aos que carregam a 
lógica da sociedade civil e àqueles que respondem aos regulamentos institucionais. Essas diversas intencionalidades formam, segundo o autor, uma alarmante heterogeneidade de estímulos que causam uma disputa simbólica. Como olhar esta junção caótica de signos? Silveira lança a pergunta e procura respondê-la através do que denominou como etnografia do olhar, ou seja, uma visão mais apurada do espaço, conseguida através do registro fotográfico e posterior análise.

Continuando com suas investigações sobre as percepções possíveis dos diversos elementos presentes na cidade, o autor elabora em seu último texto, "Uma cidade em quadro clínico", uma profunda reflexão do conceito, bastante trabalhado por Walter Benjamin, de inconsciente ótico. Neste termo é possível, segundo o autor, apresentar da melhor maneira o que representa as preocupações do filósofo alemão. A partir desta abordagem, Silveira se preocupa em problematizar a referida ideia, objetivando obter uma metodologia capaz de abarcar as "inscrições e efeitos de sentido" identificados através das fotografias - dotadas de forte componentes narrativos - que foram feitas ao longo da pesquisa.

O trabalho com as fotografias demandou duas ações metodológicas diferentes e complementares: o registro e a análise do material. A primeira foi realizada em vários momentos, o que resultou em 350 fotografias obtidas no intervalo de quatro meses. Já na segunda etapa, de edição, seleção e agrupamento, permitiu ao autor levantar a sua principal hipótese, a construção de um inconsciente ótico metropolitano. Avançando, ou delimitando, o conceito de Benjamin é operacionalizado à possível leitura e interpretação da profusão de imagens presentes nos cenários urbanos reveladas na dimensão imanente do registro fotográfico, na sucessão das fotografias e na imagem "lacunar ou ausente". Esta metodologia permite assim, revelar os nuances da cidade, suas modificações e imagens que não seriam possíveis de observar plenamente a olho nu.

Estruturalmente pode-se dividir a pesquisa de Silveira em dois momentos, no primeiro, que contém os três primeiros textos, revela-se a presença do aparelho televisivo. Não necessariamente através de sua programação, os textos aludem à força simbólica da materialidade desses media na sociedade contemporânea, das telas, que mesmo quebradas em um lixão, continuam a exalar presença constante na vida cotidiana, embalando conversas, trabalhos e a própria mediação do mundo.

$\mathrm{Na}$ segunda parte, perplexo pela quantidade de imagens que nos invadem a todo instante quando nos deslocamos pela metrópole, procura compreender as dinâmicas envolvidas nesses processos. Tentando insistentemente flagrar esses momentos, essa história que passa diante de nossos olhos e nem sequer vemos, Silveira adere à máquina. Talvez por ser justamente ela, a produtora e a consumidora, que seja capaz de apreender o que o organismo não vê.

Embora seja possível fazer essa separação de objetivos dos textos, ao lê-los outras relações aparecem, outras imagens, trazidas pelo entusiasmo do autor, que nos fazem pensar sobre os nossos hábitos e vícios comunicativos. Não à toa, a contracapa é assinada por Norval Baitello Júnior, que declara que o livro nos oferece um "duplo presente: analisa o entorno como parte da chamada mídia e leva ainda em consideração a corporeidade dos objetos da comunicação".

Comunicação que cada vez mais, e até no terreno da metrópole, é mediada pelos aparelhos, pelas imagens. E é disto que Silveira trata, deste tipo de processo comunicativo e da necessidade, cada vez mais urgente, de se elaborar métodos, teorias e novas abordagens em relação a estas condições impostas.

Recorrendo novamente a Baitello (2005), que desenvolve a teoria do pensador alemão Harry Pross, a comunicação começa e termina no corpo e é através deste corpo que Fabrício nos revela o urbano. Em seu incessante exercício benjaminiano - novamente, não à toa o filósofo é permanentemente citado - de embarcar incodicionalmente na aventura metropolitana, os ensaios nos remetem sempre à flânerie. Com sua constante agudeza e extrema sensibilidade em enxergar a cidade, o autor questiona a si próprio e também aos seus leitores sobre as novas formas possíveis de viver o mundo e a própria comunicação. 


\section{Bibliografia:}

BAITELLO, Norval. A era da iconofagia. Ensaios de comunicação e cultura. São Paulo: Hacker, 2005.

\section{Mini Currículo :}

Denise Tangerino é mestre pelo Programa de Comunicação e Práticas de Consumo da ESPM-SP, orientada pela Prof. Dra. Rose de Melo Rocha.

Diogo Andrade Bornhausen é mestrando no Programa de Estudos Pós-Graduados em Comunicação e Semiótica da PUC-SP, orientado pelo Prof. Dr. Norval Baitello Jr. Pesquisador do Centro Interdisciplinar de Semiótica da Cultura e da Mídia (Cisc). Bolsista CNPq. 